\title{
Efficient Isolation of an Anti-Cancer Sesquiterpene Lactone from Calomeria amaranthoides by Steam Distillation
}

\author{
Colin Charles Duke ${ }^{1 *}$, Caroline van Haaften ${ }^{2}$, Van Hoan Tran ${ }^{1}$ \\ ${ }^{1}$ Faculty of Pharmacy, University of Sydney, Sydney, Australia \\ ${ }^{2}$ Department of Gynaecology, Leiden University Medical Center, Leiden, The Netherlands \\ E-mail: colin.duke@sydney.edu.au \\ Received September 26, 2011; revised October 31, 2011; accepted November 9, 2011
}

\begin{abstract}
An efficient method of isolating an anti-cancer sesquiterpene lactone, eremophila-1(10)-11(13)-dien-12,8 $\beta$ olide, was developed from fresh Calomeria amaranthoides plant material on the basis of its non-polar volatile property. Steam distillation of fresh plant material gave a high recovery of sesquiterpene-rich oil, $0.56 \%$, compared with the estimated $0.66 \%$ calculated from solvent extraction of dried plant material. The sesquiterpene-rich oil containing 58\% of the sesquiterpene lactone was fractionated by the short-column vacuum chromatography method, using minimal stationary-phase and solvent, to give the sesquiterpene lactone $95 \%$ purity, yield $41 \%$.
\end{abstract}

Keywords: Sesquiterpene Lactone, Calomeria amaranthoides, Steam Distillation, Chromatography

\section{Introduction}

Calomeria amaranthoides Vent., is a shrub of the Asteraceae (Compositae) family and belongs to a monotypic genus endemic to NSW and Victoria, Australia [1]. It is a biennial plant that can grow to more than three metres high, with plume-like flowers and wrinkly leaves. The plant has a strong aromatic scent and its common name is incense plant. The chemical constituents composition of aerial parts of $C$. amaranthoides were examined initially by Zdero et al. [2], however, none the constituents reported by them were identified in the $C$. amaranthoides extracts described in a study by van Haaften et al. [3] where two main constituents isolated from the aerial parts of $C$. amaranthoides were identified as eremophila1(10)-11(13)-dien-12,8 $\beta$-olide (1) [4] and eremophila1(10), 11(13)-dien-12-oic acid (2) [5] (Figure 1). 1 and 2 had been isolated and reported previously from plants of the Asteraceae family $[4,5]$. The study by van Haaften et al. [3] showed a potent cytotoxic effect of the non-polar extract from the leaves of $C$. amaranthoides towards ovarian cancer cells. Much of the in vitro cytotoxicity towards ovarian cancer cells appeared to be due to $\mathbf{1}$. This was supported by studies in vivo where, on treatment with $\mathbf{1}$, anti-cancer effects were observed with nude mice inoculated with OVCAR3 cells intraperitoneally [3].
An ester substituted eremophilane marine natural product, cryptospaerolide, showed significant cytotoxicity towards HCT-116 human colon carcinoma cell line [6]. This finding indicates that the plant derived $\mathbf{1}$ eremophilane skeleton has potential to serve as a scaffold for synthesis of effective anti-cancer agents. Efficient methods were sought to produce larger quantities of extract of $\mathbf{1}$, required for further biological studies. The odour of the plant, the extract and $\mathbf{1}$ were very similar, so a method of isolating the volatile biologically active material by steam distillation was developed.

\section{Results and Discussion}

The yield of sesquiterpenes, $\mathbf{1}$ and $\mathbf{2}$, from fresh plant material was estimated to be approximately $0.66 \%$ based on the content of the $\mathrm{CH}_{2} \mathrm{Cl}_{2}$ extract of freshly dried leaves. Hydrodistillation conditions were initially used

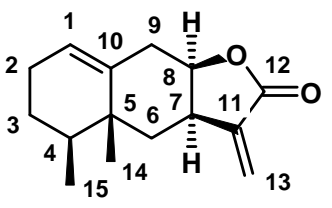

1

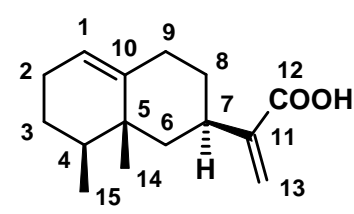

2
Figure 1. Structures of eremophila-1(10)-11(13)-dien-12,8 $\beta$ olide (1) and eremophila-1(10),11(13)-dien-12-oic acid (2). 
with a relatively large amount of plant material torn into large pieces and using minimal added water (Experiment 1, Table 1) and this resulted in relatively low recovery of sesquiterpene-rich oil steam distillate. Using less plant material and a larger volume of added water (Experiment 2, Table 1) gave a higher recovery of sesquiterpene-rich oil steam distillate, however, the yield was only about half of the estimated maximum. Separation of the sesquiterpene-rich oil from the steam distillate required solvent extraction and salting-out due to the small proportion and the stable emulsion of sesquiterpene-rich oil steam distillate. Extraction with $\mathrm{CH}_{2} \mathrm{Cl}_{2}$ alone proved to be ineffective in Experiments $1 \& 2$ as EtOAc was required to complete the extraction. Efficient extraction was achieved with EtOAc alone in later experiments. For Experiments 3 and 4 plant material was blended to a fine suspension and after the first distillation the process of adding water and distilling was repeated twice. In Experiment 3 , the yield of sesquiterpene-rich oil from the steam distillate was comparable to the estimated maximum, however, the amount of sesquiterpene-rich oil produced from the third distillation was comparable to the first and second indicating that a higher yield may have been possible. In Experiment 4 the amount of plant ma- terial was halved and this provided conditions which gave the highest yield. Most of the sesquiterpene-rich oil was obtained in the first distillation, and the amount obtained in the second distillation was approximately half that of the first and approximately halved again in the third distillation indicating that close to maximum yield is likely to have been achieved with Experiment 4. Even with the addition of $\mathrm{NaCl}$ to salt-out the sesquiterpenerich oil from the steam distillate, extraction with EtOAc to remove the cloudy emulsion was slow and a clear aqueous phase was not achieved until the third EtOAc extraction. This was an unexpected property as the two sesquiterpenes have a low polarity and are very lipophilic. The apparent affinity for aqueous media may prove a useful property in terms of increased bio-availability in the evaluation of $\mathbf{1}$ for potential application to treat cancer [3].

Short-column vacuum chromatography was selected to fractionate and refine the sesquiterpene-rich oil, as the method required a relatively small quantity of TLC grade silica gel and solvent and it was carried as a single stage large-scale separation process. A single application of this process gave good yields of highly refined 1 and $\mathbf{2}$ (Table 2). The yield and high recovery of $\mathbf{1}$ and $\mathbf{2}$ showed

Table 1. Yields of sesquiterpene-rich oil and sesquiterpene lactone (1) obtained by steam distillation processes.

\begin{tabular}{|c|c|c|c|c|c|c|c|c|c|}
\hline & steam & $\begin{array}{c}\text { fresh plant } \\
\text { material }\end{array}$ & $\begin{array}{l}\text { vol added } \\
\text { hot water }\end{array}$ & $\begin{array}{l}\text { vol steam } \\
\text { distillate }\end{array}$ & extraction & yield & oil yield & AV 1 & STDev 1 \\
\hline Expt & distillation & grams & $(\mathrm{mL})$ & $(\mathrm{mL})$ & solvent & grams & $\%$ & $* \%$ & $\%$ \\
\hline \multirow[t]{3}{*}{1} & single & 500 & 1000 & 600 & $\mathrm{CH}_{2} \mathrm{Cl}_{2}$ & 0.1803 & & 69.5 & 1.2 \\
\hline & & & & & EtOAc & 0.0287 & & 72.8 & 2.0 \\
\hline & & & & & Total & 0.209 & 0.042 & & \\
\hline \multirow[t]{3}{*}{2} & single & 345 & 2000 & 1800 & $\mathrm{CH}_{2} \mathrm{Cl}_{2}$ & 0.5802 & & 68.3 & 2.0 \\
\hline & & & & & EtOAc & 0.2933 & & 70.5 & 2.2 \\
\hline & & & & & Total & 0.8735 & 0.253 & & \\
\hline \multirow[t]{4}{*}{3} & triple & 370 & 2000 & 1500 & EtOAc & 0.8589 & & 70.2 & 2.4 \\
\hline & & & 2000 & 1600 & EtOAc & 0.5529 & & 66.5 & 1.2 \\
\hline & & & 1600 & 1600 & EtOAc & 0.5115 & & 61.9 & 1.7 \\
\hline & & & & & Total & 1.9233 & 0.520 & & \\
\hline \multirow[t]{4}{*}{4} & triple & 190 & 3000 & 2000 & EtOAc & 0.6147 & & 66.8 & 1.6 \\
\hline & & & 1600 & 1600 & EtOAc & 0.2778 & & 57.6 & 2.3 \\
\hline & & & 1500 & 1500 & EtOAc & 0.162 & & 48.9 & 2.8 \\
\hline & & & & & Total & 1.0545 & 0.555 & & \\
\hline
\end{tabular}

AV: Average; STDev: Standard deviation, *Proportion of $\mathbf{1}$ in relation to $\mathbf{1}$ plus $\mathbf{2}$ content. 
Table 2. Short-column vacuum chromatography fractionation of steam distillate from experiment 3.

\begin{tabular}{|c|c|c|c|c|c|c|c|}
\hline & Hexane & $\mathrm{CH}_{2} \mathrm{Cl}_{2}$ & EtOAc & Fract & yield* & 1 & 2 \\
\hline Fract & $(\mathrm{mL})$ & $(\mathrm{mL})$ & $(\mathrm{mL})$ & (mg) & $\%$ & $\%$ & $\%$ \\
\hline 1 & 25 & 25 & & 89 & 8 & 26 & \\
\hline 2 & 12.5 & 12.5 & & 457 & 41 & $94.7 \pm 1.8$ & \\
\hline 3 & & 25 & & 134 & 12 & $78.8 \pm 1.8$ & 20 \\
\hline 4 & & 25 & & 157 & 14 & $54.7 \pm 0.8$ & 44 \\
\hline 5 & & 25 & & 61 & 5.4 & & 92 \\
\hline 6 & & 22.5 & 2.5 & 40 & 3.6 & & 84 \\
\hline 7 & & 22.5 & 2.5 & 70 & 6.2 & & 91 \\
\hline 8 & & 20 & 5 & 31 & 2.7 & & 95 \\
\hline 9 & & 20 & 5 & 22 & 1.9 & & 95 \\
\hline 10 & & 12.5 & 12.5 & 13 & 1.2 & & 64 \\
\hline TOTAL & & & & 1074 & 95.8 & & \\
\hline
\end{tabular}

*based on the $1120.3 \mathrm{mg}$ portion of sesquiterpene-rich oil fractionated.

that both of these sesquiterpenes were stable under the steam distillation conditions. There are no references for the steam distillation of sesquiterpene lactones in the literature as in many cases thermal degradation occurs, commonly by rearrangement, dehydration and elimination processes [7]. The volatile nature of both $\mathbf{1}$ and $\mathbf{2}$ may explain their loss over time from stored dried plant material [3].

\section{Conclusions}

Steam distillation by the hydro-distillation method is a convenient and efficient method to isolate from fresh plant material a highly refined product free from waxes and other non-volatile material. The pale yellow liquid product contained approximately 58\% 1 with most of the remaining material being 2 . Through the application of short-column vacuum chromatography both $\mathbf{1}$ and $\mathbf{2}$ are rapidly and efficiently refined to high levels of purity.

This method is of great importance for obtaining the larger quantities of $\mathbf{1}$ required for further studies on the treatment of ovarian and other cancers.

\section{Experimental Section}

\subsection{Plant Material}

A voucher specimen of Calomeria amaranthoides, collected near Old Bell's Line of Road, Mount Tomah NSW
2758, Australia, is held in the John Ray Herbarium, University of Sydney, Collection number: Silvester 11011801.

Leaves and stems of the upper aerial parts of C. amaranthoides, gathered in the Blue Mountains (Mount Tomah, NSW, Australia), were kept fresh at $4^{\circ} \mathrm{C}$ for no more than 4 days before steam distillation.

\subsection{H-NMR Analyses}

${ }^{1} \mathrm{H}-\mathrm{NMR}$ spectroscopy was performed using a Varian $400 \mathrm{MHz}$ instrument (Palo Alto, CA, USA). The solvent used was $\mathrm{CDCl}_{3}$ and the spectra were measured in parts per million (ppm) referenced to tetramethylsilane (TMS $=0 \mathrm{ppm}$ ).

Short-Column Vacuum Chromatography (SCVC) [8] was performed using a column packed with TLC-grade silica gel H60 (Merck, Darmstadt, Germany) and applying a step-wise gradient of solvents with increasing polarity.

$\mathbf{1}$ and $\mathbf{2}$ content of the steam distillate and chromatographic fractions were determined by integration of proton signals for $\mathrm{H}-1, \mathrm{H}-13$ and $\mathrm{H}-13$ ' for both sesquiterpenes. The content based on the integration for each proton type was calculated as the average and standard deviation.

\subsection{Steam Distillation Method and Apparatus}

Plant material was finely chopped in deionised water us- 
ing a 550 W Breville Blender. Steam distillation was carried out by the hydrodistillation method at atmospheric pressure. Heat was provided using the lower mantle setting of a $5 \mathrm{~L}$ heating mantle. Apparatus consisted of a B34 $5 \mathrm{~L}$ round bottom flask, stillhead, a double-coiled single-jacketed water cooled condenser and a receiver head. The $5 \mathrm{~L} \mathrm{RB}$ flask and stillhead were wrapped with a single layer of aluminium foil throughout the distillation.

\subsection{Steam Distillation of Leaves and Stems (Optimised Procedure, Experiment 3)}

Fresh leaves and stems (370 g) and hot water (2000 mL) were blended to a fine suspension, placed in a 5 litre flask which was heated and the water distilled conden-

CD102-1-2_Proton_01
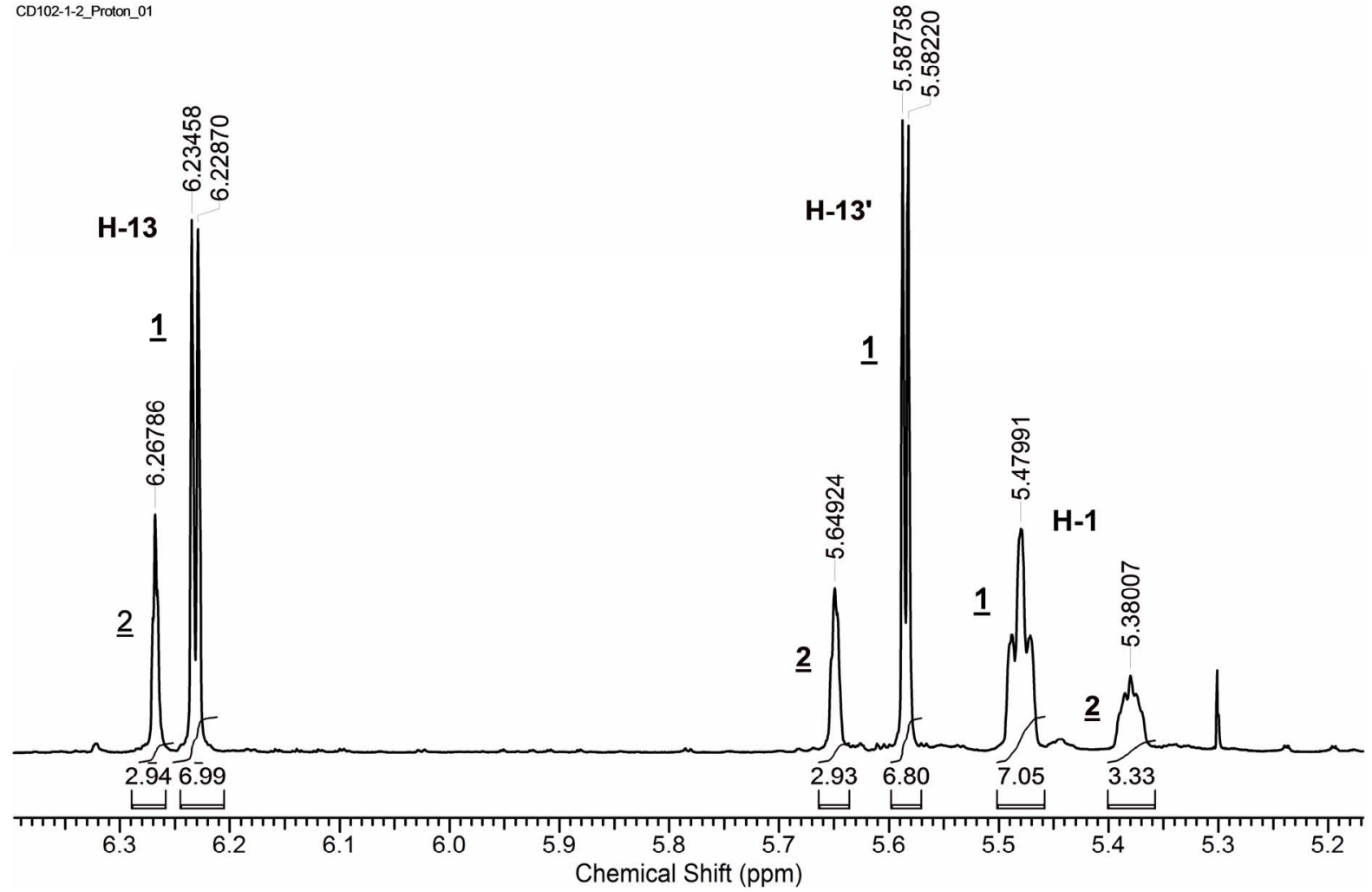

Figure 2. Partial ${ }^{1} \mathrm{H}$-NMR spectrum of sesquiterpene-rich oil steam distillate showing an example integration of the $\mathrm{H}-1, \mathrm{H}-13$ and H-13' signal to determine the 1 and 2 content.

A portion of the EtOAc extracted steam distillates were combined (1.12 g, ${ }^{1} \mathrm{H}-\mathrm{NMR}$ analysis 1 69.4\% \pm $1.4 \%$ ) and fractionated by normal-phase short column vacuum chromatography, silica gel $\mathrm{H}$, diameter $50 \mathrm{~mm}$, height $25 \mathrm{~mm}$, eluted with a stepwise solvent gradient of hexane:dichloromethane 1:1 (50 mL and $25 \mathrm{~mL}$ ); dichloromethane $(3 \times 25 \mathrm{~mL})$; dichloromethane:ethyl acetate 9:1 $(2 \times 25 \mathrm{~mL})$; dichloromethane:ethyl acetate 4:1 $(2 \times 25 \mathrm{~mL})$; dichloromethane:ethyl acetate $1: 1(2 \times 25$

sate $(1500 \mathrm{~mL})$ collected. The apparatus was allowed to cool and hot water was added to the $5 \mathrm{~L}$ flask which was again heated and further water distilled condensate (1600 $\mathrm{mL}$ ) collected. The process described in the last sentence was repeated giving 3 lots of condensate in total. Each lot of condensate was mixed with $\mathrm{NaCl}$ (approx. $12.5 \mathrm{~g}$ per $100 \mathrm{~mL}$ of condensate) until the $\mathrm{NaCl}$ had all dissolved, then, thrice extracted with EtOAc $(3 \times 50 \mathrm{~mL})$. The pooled EtOAc for each lot was collected, dried with anhydrous $\mathrm{Na}_{2} \mathrm{SO}_{4}$, filtered and concentrated to a very pale yellow slightly viscous liquid $(0.86$ g, 0.55 g, 0.51 g, total $1.9 \mathrm{~g}$ ). ${ }^{1} \mathrm{H}-\mathrm{NMR}$ analysis (Figure 2) indicated that the EtOAc extracted pale yellow viscous liquid was mainly a mixture of 1 (62\% to $70 \%)$ and 2 (28\% to $30 \%)$

(Table 1).

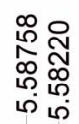


$\mathrm{mg}$ ); F8-F10 (49.6 mg). Recovery, as a proportion of the total weight oil, $95.8 \% .{ }^{1} \mathrm{H}-\mathrm{NMR}$ analysis showed that fractions 2 consisted mainly of $1,94.7 \%$. Fractions 7 to 9 (122 mg) consisted mainly of 2, 91-95\% (Table 2). The sesquiterpene-rich oil from experiment 3 was found to consist of approximately $85 \%$ of a mixture of compounds $\mathbf{1}$ and $\mathbf{2}$ from ${ }^{1} \mathrm{H}$ NMR analyses of Fractions 1 to 10.

\subsection{Cold Extraction of Leaves and Stems with Dichloromethane}

Fresh plant material (208 g) was dried over a few days in subdued light to give dried plant material (46.7 g, 22.5 $\%)$. A portion of this dried plant material (1.63 g) was extracted with $\mathrm{CH}_{2} \mathrm{Cl}_{2}(100 \mathrm{~mL})$ to give yellow-brown oil (62.6 mg, 3.9\%). ${ }^{1} \mathrm{H}-\mathrm{NMR}$ analysis indicated that approximately $75 \%$ of the mixture was $\mathbf{1}$ and $\mathbf{2}$ and the remainder was a complex mixture of unidentified material.

Yields and Proportions of $\mathbf{1}$ and $\mathbf{2}$ steam distilled from fresh plant material under a range of conditions are summarised in Table 1.

\section{Acknowledgements}

We thank Ms Karen Silvester for providing the Calomeria amaranthoides plant material for this study.

\section{References}

[1] C. F. Puttock, "Flora of Victoria," In: N. G. Walsh and T. J. Entwisle, Eds., Inkata Press, Melbourne, Vol. 4, 1999, p. 1.
[2] C. Zdero, F. Bohlmann, A. Anderberg and R. M. King, "Eremophilane Derivatives and Other Constituents from Haeckeria Species and Further Australian Inuleae,” Phytochemistry, Vol. 30, No. 8, 1991, pp. 2643-2650. doi:10.1016/0031-9422(91)85114-F

[3] C. van Haaften, C. C. Duke, A. M. Weerheim, N. P. M. Smit, P. M. M. van Haard, F. Darroudi and B. J. M. Z. Trimbos, "Potent Cytotoxic Effects of Calomeria Amaranthoides on Ovarian Cancers,” Journal of Experimental \& Clinical Cancer Research, Vol. 30, No. 1, 2011, p. 29. doi:10.1186/1756-9966-30-29

[4] N. Tanaka, T. Yazawa, K. Aoyama and T. Murakami, "Chemical Studies on the Constituents of Xanthium Canadense Mill,” Chemical \& Pharmaceutical Bulletin, Vol. 24, 1976, pp. 1419-1421.

[5] F. Bohlmann, C. Zdero and M. Silva, "Two Further Eremophilane Derivatives from Tessaria Absynthioides," Phytochemistry, Vol. 16, 1977, pp. 1302-1303. doi:10.1016/S0031-9422(00)94385-1

[6] H. Oh, P. R. Jensen, B. T. Murphy, C. Fiorilla, J. F. Sullivan, T. Ramsey and W. Fenical, "Cryptosphaerolide, a Cytotoxic Mcl-1 Inhibitor from a Marine-Derived Ascomycete Related to the Genus Cryptosphaeria,” Journal of Natural Products, Vol. 73, No. 5, 2010, pp. 998-1001. doi:10.1021/np1000889

[7] J. C. Spitzer and C. Steelink, "Isolation of Matricin from Artemisia Caruthii,” Journal of Pharmaceutical Sciences, Vol. 56, No. 5, 1967, pp. 650-651. doi:10.1002/jps.2600560526

[8] C. C. Duke and R. J. Wells, "Investigation of Readily Available Chiral Compounds for Preparative Scale Resolutions,” Australian Journal of Chemistry, Vol. 40, No. 10, 1987, pp. 1641-1654. doi:10.1071/CH9871641 